\title{
Prognostic Value and Computer Image Analysis of p53 in Mantle cell Lymphoma
}

\author{
Li-Min Gao ( $\sim$ hxgaolimin@126.com ) \\ West China Hospital of Sichuan University \\ Yue-Hua Zhang \\ West China Hospital of Sichuan University \\ Xiao-Yu Xiang \\ West China Hospital of Sichuan University \\ Wei-Ping Liu \\ West China Hospital of Sichuan University \\ Wen-Yan Zhang \\ West China Hospital of Sichuan University
}

\section{Research Article}

Keywords: Mantle cell lymphoma, P53, Prognosis, Computer image analysis

Posted Date: January 18th, 2022

DOI: https://doi.org/10.21203/rs.3.rs-970717/v2

License: (c) (i) This work is licensed under a Creative Commons Attribution 4.0 International License. Read Full License 


\section{Abstract}

Background: P53 has different prognostic cutoff values in different mantle cell lymphoma (MCL) studies, and p53 immunohistochemistry (IHC) interpretation is still based on semiquantitative estimation, which might be inaccurate. This study aimed to investigate the optimal cutoff value of p53 for predicting prognosis and the possible use of computer image analysis to identify the positive rate of p53 in patients with MCL.

Methods: We used QuPath software to determine the p53 positive rate and compared it to the data obtained by manual counting and semiquantitative estimation. Using the Youden index and Kaplan-Meier survival curve analysis, we generated survival curves. The chisquared $\left(\chi^{2}\right)$ test was used to compare MCL cell morphology with p53. Spearman rank correlation test and Bland-Altman analysis were used to compare manual counting, computer image analysis and semiquantitative estimation.

Results: The optimal cutoff value of p53 for predicting prognosis was $20 \%$ in MCL patients. Patients with $p 53 \geq 20 \%$ had a significantly worse overall survival (OS) than those with $p 53<20 \%(P<0.0001)$. MCL patients with blastoid/pleomorphic variant cell morphology had more p53 $\geq 20 \%$ than the classical type $(P<0.0001)$. There was a strong correlation between computer image analysis and manual counting of $\mathrm{p} 53$ from the same areas in MCL tissues (Spearman's rho $=0.966, \mathrm{P}<0.0001$ ).

Conclusions: MCL patients with p53 $\geq 20 \%$ have a shorter OS and a tendency toward the blastoid/pleomorphic variant. Computer image analysis could determine the actual positive rate of p53 and is a more attractive alternative than semiquantitative estimation in MCL.

\section{Introduction}

Mantle cell lymphoma $(\mathrm{MCL})$ is an aggressive B-cell non-Hodgkin lymphoma (NHL) and comprises approximately $3-10 \%$ of $\mathrm{NHLs}{ }^{1-3}$. The clinical prognoses of MCL are heterogeneous, and risk stratification is based on the clinical indices comprising the Mantle Cell Lymphoma Prognostic Index (MIPI) and a combined biological MIPI, including Ki67 ${ }^{4-6}$. However, risk stratification might be further improved by biological markers, such as p53. P53 protein expression might serve as an alternative marker for TP53 gene mutations ${ }^{7-9}$ and has been confirmed to be of prognostic value independent of the biological MIPI score in multiple MCL studies $7,10-12$. However, the prognostic cutoff values of p53 differ in different studies; thus, its use is still controversial. Furthermore, p53 immunohistochemistry (IHC) interpretation is still based on semiquantitative estimations that are inaccurate because of more considerable interobserver variability. Therefore, practical and efficient means for precisely interpreting the positive rate of p53 with less interobserver variability would be of great value for diagnosing MCL.

In the present study, we aimed to investigate the prognostic cutoff value of p53 in MCL. Moreover, we applied computer image analysis software to calculate p53 in MCL patients and compared the data to the results obtained from manual counting and semiquantitative estimation in routine clinical diagnostics.

\section{Results}

\section{Patient characteristics}

The cohort included $65 \mathrm{MCL}$ patients. The male to female ratio was $2.61: 1$, and the median age was 63 . Thirty-eight (58\%) patients were at Ann Arbor stage $\mathbb{X}-\mathbb{Z}$ and $27(42 \%)$ were at stage $\mathbb{X}-\mathbb{Z}$. From these patients, $43(66 \%)$ tumor tissue specimens were derived from lymph nodes, and others were derived from the gastrointestinal tract, tonsil, nasopharynx, bone marrow, etc. The tumor cell morphology of 36 (55\%) patients was the classical type, and $29(45 \%)$ patients had blastoid/pleomorphic variants. Follow-up data were obtained for all 65 patients, and 51 (78\%) patients with MCL had died (Table 1). 
Clinical and pathological features of MCL patients.

\begin{tabular}{|llll|}
\hline Category & & $\mathbf{n}$ & $\%$ \\
\hline Sex & Male & 47 & 72 \\
\hline Age [median (range)] & Female & 18 & 28 \\
\hline Ann Arbor stage & $\mathbb{X}-\mathbb{Z}$ & $63(38-84)$ & $\mathrm{NA}$ \\
\hline & $\mathbb{X}-\mathbb{Z}$ & 38 & 58 \\
\hline Tumor tissue type & Lymph node & 27 & 42 \\
\hline & Gastrointestinal tract & 43 & 66 \\
\hline & Tonsil & 9 & 14 \\
\hline Nasopharynx & 5 & 8 \\
\hline Cell morphology & Bone marrow & 2 & 3 \\
\hline & Others & 2 & 3 \\
\hline Survival state & Blassical type & 4 & 6 \\
\hline MCL, mantle cell lymphoma; NA, not applicable. & 36 & 55 \\
\hline & Surviving & 29 & 45 \\
\hline & Deceased & 14 & 22 \\
\hline
\end{tabular}

\section{Manual counting, computer image analysis and semiquantitative estimation of p53 and their correlation with survival and cell morphology}

Figure 1 shows images based on manual counting (Figure 1A) and the computer image analysis (Figure 1B) of identical images from a representative region. The median p53 assessed by manual counting of at least 1000 tumor cells was $43.1 \%$, and the mean was $45.0 \%$ (range $0-100 \%$ ). The median p53 calculated by computer image analysis of the same areas by manual counting was $53.3 \%$, with a mean of $48.2 \%$ (range $0.1-100 \%$ ). The p53 acquired by semiquantitative estimation displayed a median of $40 \%$ and a mean of $39.4 \%$ (range $0-100 \%$ ).

Manual counting, computer image analysis and semiquantitative estimation of p53 can predict OS. Each of these methods showed an AUC > 0.85 on ROC curves $(\mathrm{P}<0.0001$; Figure 2, Table 2$)$. The optimal p53 cutoff for predicting OS were determined for each method. For manual counting, the cutoff value was $16.20 \%$, sensitivity was $80.39 \%$, and specificity was $100 \%$. For computer image analysis, the cutoff value was $17.66 \%$, sensitivity was $74.51 \%$, and specificity was $100 \%$. For semiquantitative estimation, the cutoff value was $5.00 \%$, sensitivity was $76.47 \%$, and specificity was $92.86 \%$ (Table 2). As manual counting and computer image analysis are more precise than semiquantitative estimation, we used the approximate value of manual counting and computer image analysis, $20 \%$, as the cutoff value of p53 for subsequent analysis. 
Table 2

Diagnostic performance of p53 as measured by different methods.

\begin{tabular}{|c|c|c|c|c|c|c|}
\hline & $\operatorname{AUC}(95 \% \mathrm{Cl})$ & $\mathbf{P}$ & $\begin{array}{l}\text { Youden } \\
\text { index }\end{array}$ & $\begin{array}{l}\text { Optimal } \\
\text { cutoff }\end{array}$ & Sensitivity $(95 \% \mathrm{Cl})$ & Specificity $(95 \% \mathrm{Cl})$ \\
\hline Manual counting & $\begin{array}{l}0.873 \\
(0.767-0.943)\end{array}$ & $<0.0001$ & 0.8039 & $16.20 \%$ & $\begin{array}{l}80.39 \%(66.9 \% \\
-90.2 \%)\end{array}$ & $\begin{array}{l}100 \%(76.8 \% \\
-100 \%)\end{array}$ \\
\hline $\begin{array}{l}\text { Computer image } \\
\text { analysis }\end{array}$ & $\begin{array}{l}0.853 \\
(0.743-0.929)\end{array}$ & $<0.0001$ & 0.7451 & $17.66 \%$ & $\begin{array}{l}74.51 \%(60.4 \%- \\
85.7 \%)\end{array}$ & $\begin{array}{l}100 \%(76.8 \%- \\
100 \%)\end{array}$ \\
\hline $\begin{array}{l}\text { Semiquantitative } \\
\text { estimation }\end{array}$ & $\begin{array}{l}0.856 \\
(0.747-0.931)\end{array}$ & $<0.0001$ & 0.6933 & $5.00 \%$ & $\begin{array}{l}76.47 \%(62.5 \%- \\
87.2 \%)\end{array}$ & $\begin{array}{l}92.86 \%(66.1 \%- \\
99.8 \%)\end{array}$ \\
\hline
\end{tabular}

To assess the prognosis of these three methods, we performed survival analysis. Kaplan-Meier survival curve analysis showed that patients with $\mathrm{p} 53<20 \%$ had a significantly longer OS than patients with p53 $\geq 20 \%(\mathrm{P}<0.0001$, Figure $3 \mathrm{~A}-\mathrm{C})$. Moreover, patients with blastoid/pleomorphic MCL had shorter OS than those with classical MCL $(P<0.0001$, Figure 3D). Blastoid/pleomorphic variant MCL patients had more p53 $\geq 20 \%$ than classical type patients $(P<0.0001$, Table 3$)$.

Table 3

Correlation analysis of $\mathrm{p} 53$ and cell morphology.

\begin{tabular}{|c|c|c|c|c|c|c|c|c|c|c|c|c|}
\hline \multirow[t]{2}{*}{ Cell morphology } & \multicolumn{4}{|c|}{ P53 by manual counting } & \multicolumn{4}{|c|}{$\begin{array}{l}\text { P53 by computer image } \\
\text { analysis }\end{array}$} & \multicolumn{4}{|c|}{$\begin{array}{l}\text { P53 by semiquantitative } \\
\text { estimation }\end{array}$} \\
\hline & $\hat{20 \%}$ & $\underset{20 \%}{\geq}$ & $x^{2}$ & $\mathbf{P}$ & $20 \%$ & $\underset{20 \%}{\geq}$ & $x^{2}$ & $\mathbf{P}$ & 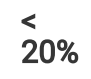 & $\underset{20 \%}{\geq}$ & $\chi^{2}$ & $\mathbf{P}$ \\
\hline Classical type & 23 & 13 & \multirow[t]{2}{*}{21.703} & \multirow{2}{*}{$\begin{array}{l}< \\
0.0001\end{array}$} & 23 & 13 & \multirow[t]{2}{*}{21.703} & \multirow{2}{*}{$\begin{array}{l}< \\
0.0001\end{array}$} & 26 & 10 & \multirow[t]{2}{*}{27.523} & \multirow{2}{*}{$\begin{array}{l}< \\
0.0001\end{array}$} \\
\hline Blastoid/pleomorphic variant & 2 & 27 & & & 2 & 27 & & & 2 & 27 & & \\
\hline
\end{tabular}

\section{Correlation between manual counting, computer image analysis and semiquantitative estimation}

There was a strong correlation between manual counting and the computer image analysis of p53 in tidentical areas (Spearman's rho = $0.966, \mathrm{P}<0.0001$, Figure $4 \mathrm{~A}$ ). There was a significant correlation between manual counting and semiquantitative estimation (Spearman's rho $=0.938, \mathrm{P}<0.0001$, Figure 4B), albeit weaker than the correlation between manual counting and computer image analysis. Moreover, we found a significant correlation between semiquantitative estimation and computer image analysis (Spearman's rho $=0.898$, $\mathrm{P}<0.001$, Figure 4C).

Bland-Altman plots comparing manual counting with the computer image analysis of identical areas revealed a tendency toward a higher evaluation of p53 by computer image analysis (Figure 4D), and comparing manual counting p53 with semiquantitative estimation revealed a tendency toward a lower evaluation of p53 by semiquantitative estimation (Figure 4E). We also used the Bland-Altman plot to compare computer image analysis with the semiquantitative estimation of identical areas. The results revealed a tendency toward a lower evaluation of p53 by semiquantitative estimation (Figure 4F).

\section{Discussion}

In this study, we demonstrated that $20 \%$ could be used as the optimal cutoff value for determining the prognosis of MCL. MCL patients with p53 $\geq 20 \%$ had a shorter OS than patients with p53 < 20\%. In addition, patients with blastoid/pleomorphic variants of MCL tended to have p53 $\geq 20 \%$. We also verified the possibility of computer image analysis software to count p53 in patients with MCL.

IHC staining for p53 is a promising tool for predictive purposes, as it serves as an alternative marker for TP53 mutations and $17 p$ deletions ${ }^{7-}$ 9, 13 . In MCL, the prognostic significance of the immunohistochemical expression of p53 has been studied (Table 4). Rodrigues et al. also used manual counting and computer image analysis for the immunohistochemical counting of p53 and prognosis analysis ${ }^{7}$. They defined 
$30 \%$ as the prognostic cutoff value of $\mathrm{p} 53$, which is based on a previous publication ${ }^{11}$ and the routine clinical practices at Lund University Hospital. However, the prognostic cutoff values of p53 in MCL in other studies are controversial, ranging from $1 \%-50 \%$, and the criteria for defining these cutoff values are unclear ${ }^{10-12,14}$. We used manual counting and computer image analysis to count the positive rate of p53 and calculated the cutoff values for predicting OS with the optimal specificity and sensitivity through the Youden index. Manual counting was $16.20 \%$, and computer image analysis was $17.66 \%$. To facilitate clinical application, we used $20 \%$ as the cutoff value of p53 for survival analysis, and the results revealed that MCL patients with p53 $\geq 20 \%$ had a worse prognosis than those with p $53<20 \%$. In addition, we also found that p53 $\geq 20 \%$ was associated with blastoid/pleomorphic morphology, which is consistent with previous studies ${ }^{12,13,15}$.

Table 4

Summary of p53 cutoff values and the prognostic significance of MCL cases from the literature and our study.

\begin{tabular}{|c|c|c|c|c|}
\hline \multirow[t]{2}{*}{ Author } & \multirow[t]{2}{*}{ Cases } & \multicolumn{3}{|c|}{ P53 immunohistochemistry } \\
\hline & & Cut off value & Positive rate & Prognostic significance \\
\hline Our study & 65 & $20 \%$ & $40 / 65$ & Worse \\
\hline Aukema SM 10 & 365 & $50 \%$ & $16 / 365$ & Worse \\
\hline Rodrigues $\mathrm{JM}^{7}$ & 317 & $30 \%$ & $42 / 317$ & Worse \\
\hline Nordström L ${ }^{11}$ & 93 & $30 \%$ & $10 / 93$ & Worse \\
\hline Choe JY ${ }^{12}$ & 62 & $30 \%$ & - & Worse \\
\hline Abrisqueta $P^{21}$ & 40 & $1 \%$ & $5 / 40$ & Worse \\
\hline
\end{tabular}

Manual counting is very time-consuming and probably not applicable in routine clinical tests. Thus, we compared three methods of p53 counting to define a simple and accurate method. We confirmed that p53 by computer image analysis was more precise for prognosis prediction and had a stronger correlation with manual counting than semiquantitative estimation. Computer image analysis of p53 could count larger tumor regions than manual counting, making it more representative in assessing the percentage of p53-positive cells within the tumor. Additionally, computer image analysis is faster than manual counting and creates repeatable results for retrospection.

The computer image analysis revealed a tendency toward slightly higher estimates of p53 compared to manual counting. Potential reasons for the overestimation of p53 may include positively-stained background cells that were miscalled tumor cells and debris that was miscalled positive staining ${ }^{16}$. Therefore, computer image analysis could possibly benefit from strict quality control of the IHC staining method.

The limitation of computer image analysis is the inability to distinguish between different cell types such as normal cells and tumor cells ${ }^{17}$. Consequently, representative regions of lymphoma must be chosen carefully by pathologists. While pathologists choose the representative region of lymphoma, this would not be a disadvantage in MCL because the reactive cell number is low in MCL ${ }^{18}$.

In conclusion, we demonstrated that MCL patients with p53 $\geq 20 \%$ had a shorter OS and a tendency for the blastoid/pleomorphic variant. Furthermore, computer image analysis of p53 is more precise than semiquantitative estimation and can be applied to the interpretation of p53 IHC staining in patients with MCL.

\section{Methods}

\section{Patients}

A total of $65 \mathrm{MCL}$ specimens was obtained from the Department of Pathology, West China Hospital of Sichuan University from 2014 to 2021. All cases were newly diagnosed and reviewed by trained pathologists according to the 2016 World Health Organization (WHO) classification for tumors of hematopoietic and lymphoid tissues ${ }^{19}$. Anonymous data regarding sex, age, Ann Arbor stage, tumor tissue type, tumor cell morphology, and survival time were obtained retrospectively from the patients' medical records and telephone follow-ups. All patients were followed up from the date of diagnosis to July 31, 2021.

The Institutional Review Board of West China Hospital of Sichuan University approved this study (registration number: WCH2021-00333). All recruited patients gave written informed consent following the Declaration of Helsinki. 


\section{Immunohistochemistry staining of p53}

The EliVision method was used for IHC staining of $p 53^{20}$. Briefly, the paraffin blocks were cut into $4 \mu \mathrm{m}$ sections and pretreated in ethylenediaminetetraacetic acid (EDTA) buffer at pH 9.0 for 20 minutes. Then, they were incubated with p53 at a dilution of 1:200 (clone DO7; MXB Biotechnologies, Fuzhou, China) and 3,3'-diaminobenzidine (DAB) chromogen. Finally, they were counterstained with hematoxylin and rinsed with deionized water. The expression of p53 was detected in the tuomr cell nucleus. Each slide was scanned by the Hamamatsu Digital Slide Scanner NanoZoomer 2.0-HT C9600-13.

\section{Manual counting, computer image analysis and semiquantitative estimation of p53-positive cells}

Manual counting and computer image analysis of each image were performed using QuPath software (version 0.1.2) ${ }^{21,22}$. Representative regions from each slide were annotated by an experienced pathologist and a Ph.D. student. Regions involving a high density of lymphoma cells were chosen, and hotspot areas were avoided. Images were extracted from the typical region, and identical areas were selected for random manual counting and computer image analysis. When manually counting the selected images, at least 1000 tumor cells were acquired in each slide. Hematopathologists chose the representative areas and obtained semiquantitative estimates of p53.

\section{Statistical analysis}

Overall survival (OS) was defined as the number of days from diagnosis to the date of death or final follow-up. The sensitivity and specificity of p53 were tested by assessing the area under the ROC curve (AUC). Furthermore, the Youden index and optimal cutoff value were calculated using the DeLong test ${ }^{23}$. Survival curves were generated using the Kaplan-Meier survival analysis method, and the log-rank test was used to examine differences in OS. Comparisons of cell morphology and p53 were conducted using the chi-squared $\left(\chi^{2}\right)$ test. The Spearman rank correlation test was used to calculate the correlation between manual counting, computer image analysis, and semiquantitative estimation. Bland-Altman analysis was used for comparison of manual counting, computer image analysis and semiquantitative estimation 24,25 . Statistical analyses were performed using MedCalc 20.009 software (MedCalc Software Ltd), and P $<0.05$ was considered statistically significant.

\section{Abbreviations}

MCL: mantle cell lymphoma; OS: overall survival; $\chi 2$ : chi-squared; NHL: non-Hodgkin lymphoma; MIPI: Mantle Cell Lymphoma Prognostic Index; IHC: immunohistochemistry; WHO: World Health Organization; EDTA: ethylenediaminetetraacetic acid; DAB: diaminobenzidine; AUC: area under the ROC curve; NA: Not Applicable; $\mathrm{Cl}$, confidence interval.

\section{Declarations}

\section{Acknowledgements}

Not applicable.

\section{Author contributions}

YHZ, LMG and WPL contributed to the conceptual design of the study. YHZ and XYX were involved in data acquisition. YHZ, WYZ and LMG were involved in data analysis and interpretation. YHZ and LMG were involved in writing and editing the manuscript. YHZ, XYX, WYZ, LMG and WPL reviewed the manuscript. This study was supervised by WPL and LMG.

\section{Funding}

This study was supported by the national natural science foundation of China (81900197) and Science and Technology Program of Sichuan Province (2020YJ0104). 
The authors declare that they have no competing interests related to the present study.

\section{Ethics approval and consent to participate}

The present study was approved by the Institutional Review Board of West China Hospital of Sichuan University (WCH2021-00333). All subjects signed informed consent forms before participating.

\section{Consent for publication}

All subjects signed informed consent forms before participating.

\section{Availability of data and materials}

The datasets used and/or analyzed during the current study are available from the corresponding author on reasonable request.

\section{References}

1. Jain, P. \& Wang, M. Mantle cell lymphoma: 2019 update on the diagnosis, pathogenesis, prognostication, and management. American journal of hematology 94, 710-725, doi:10.1002/ajh.25487 (2019).

2. Hermine, $\mathrm{O}$. et al. Addition of high-dose cytarabine to immunochemotherapy before autologous stem-cell transplantation in patients aged 65 years or younger with mantle cell lymphoma (MCL Younger): a randomised, open-label, phase 3 trial of the European Mantle Cell Lymphoma Network. Lancet (London, England) 388, 565-575, doi:10.1016/s0140-6736(16)00739-x (2016).

3. LI, X.-q., LI, G.-d., GAO, Z.-f., ZHOU, X.-g. \& ZHU, X.-z. Distribution pattern of lymphoma subtypes in China: A nationwide multicenter study of 10002 cases. Journal of Diagnostics Concepts \& Practice 11, 111-115 (2012).

4. Hoster, E. et al. A new prognostic index (MIPI) for patients with advanced-stage mantle cell lymphoma. Blood 111, 558-565, doi:10.1182/blood-2007-06-095331 (2008).

5. Hoster, E. et al. Prognostic Value of Ki-67 Index, Cytology, and Growth Pattern in Mantle-Cell Lymphoma: Results From Randomized Trials of the European Mantle Cell Lymphoma Network. Journal of clinical oncology: official journal of the American Society of Clinical Oncology 34, 1386-1394, doi:10.1200/jco.2015.63.8387 (2016).

6. Dreyling, M. et al. Newly diagnosed and relapsed mantle cell lymphoma: ESMO Clinical Practice Guidelines for diagnosis, treatment and follow-up. Annals of oncology: official journal of the European Society for Medical Oncology 28, iv62-iv71, doi:10.1093/annonc/mdx223 (2017).

7. Rodrigues, J. M. et al. p53 is associated with high-risk and pinpoints TP53 missense mutations in mantle cell lymphoma. British journal of haematology 191, 796-805, doi:10.1111/bjh.17023 (2020).

8. Stefancikova, L. et al. Loss of the p53 tumor suppressor activity is associated with negative prognosis of mantle cell lymphoma. International journal of oncology 36, 699-706, doi:10.3892/ijo_00000545 (2010).

9. Jing, C., Zheng, Y., Feng, Y., Cao, X. \& Xu, C. Prognostic significance of p53, Sox11, and Pax5 co-expression in mantle cell lymphoma. Scientific reports 11, 11896, doi:10.1038/s41598-021-91433-7 (2021).

10. Aukema, S. M. et al. Expression of TP53 is associated with the outcome of MCL independent of MIPI and Ki-67 in trials of the European MCL Network. Blood 131, 417-420, doi:10.1182/blood-2017-07-797019 (2018).

11. Nordström, L. et al. SOX11 and TP53 add prognostic information to MIPI in a homogenously treated cohort of mantle cell lymphoma-a Nordic Lymphoma Group study. British journal of haematology 166, 98-108, doi:10.1111/bjh.12854 (2014).

12. Choe, J. Y. et al. MYC overexpression correlates with MYC amplification or translocation, and is associated with poor prognosis in mantle cell lymphoma. Histopathology 68, 442-449, doi:10.1111/his.12760 (2016).

13. Slotta-Huspenina, J. et al. The impact of cyclin D1 mRNA isoforms, morphology and p53 in mantle cell lymphoma: p53 alterations and blastoid morphology are strong predictors of a high proliferation index. Haematologica 97, 1422-1430, doi:10.3324/haematol.2011.055715 (2012).

14. Abrisqueta, P. et al. Observation as the initial management strategy in patients with mantle cell lymphoma. Annals of oncology: official journal of the European Society for Medical Oncology 28, 2489-2495, doi:10.1093/annonc/mdx333 (2017).

15. Kimura, Y. et al. Mantle cell lymphoma shows three morphological evolutions of classical, intermediate, and aggressive forms, which occur in parallel with increased labeling index of cyclin D1 and Ki-67. Cancer science 101, 806-814, doi:10.1111/j.1349-

Page $7 / 11$ 
7006.2009.01433.x (2010).

16. Naso, J. R. et al. Automated PD-L1 Scoring for Non-Small Cell Lung Carcinoma Using Open-Source Software. Pathology oncology research: POR 27, 609717, doi:10.3389/pore.2021.609717 (2021).

17. Duan, K. et al. The value of GATA6 immunohistochemistry and computer-assisted diagnosis to predict clinical outcome in advanced pancreatic cancer. Scientific reports 11, 14951, doi:10.1038/s41598-021-94544-3 (2021).

18. Klapper, W. Histopathology of mantle cell lymphoma. Seminars in hematology 48, 148-154, doi:10.1053/j.seminhematol.2011.03.006 (2011).

19. Swerdlow, S. H., Campo, E., Harris, N. L., Jaffe, E. S. \& Pileri, S. A. WHO Classification of Tumours of Haematopoietic and Lymphoid Tissues. Revised 4th Edition. (IARC press, 2017).

20. Kämmerer, U. et al. A new rapid immunohistochemical staining technique using the EnVision antibody complex. The journal of histochemistry and cytochemistry: official journal of the Histochemistry Society 49, 623-630, doi:10.1177/002215540104900509 (2001).

21. Bankhead, P. et al. QuPath: Open source software for digital pathology image analysis. Scientific reports 7, 16878, doi:10.1038/s41598017-17204-5 (2017).

22. Paulik, R. et al. An optimized image analysis algorithm for detecting nuclear signals in digital whole slides for histopathology. Cytometry. Part A: the journal of the International Society for Analytical Cytology 91, 595-608, doi:10.1002/cyto.a.23124 (2017).

23. DeLong, E. R., DeLong, D. M. \& Clarke-Pearson, D. L. Comparing the areas under two or more correlated receiver operating characteristic curves: a nonparametric approach. Biometrics 44, 837-845 (1988).

24. Bland, J. M. \& Altman, D. G. Measuring agreement in method comparison studies. Statistical methods in medical research 8, 135-160, doi:10.1177/096228029900800204 (1999).

25. Bland, J. M. \& Altman, D. G. Statistical methods for assessing agreement between two methods of clinical measurement. Lancet (London, England) 1, 307-310 (1986).

Figures

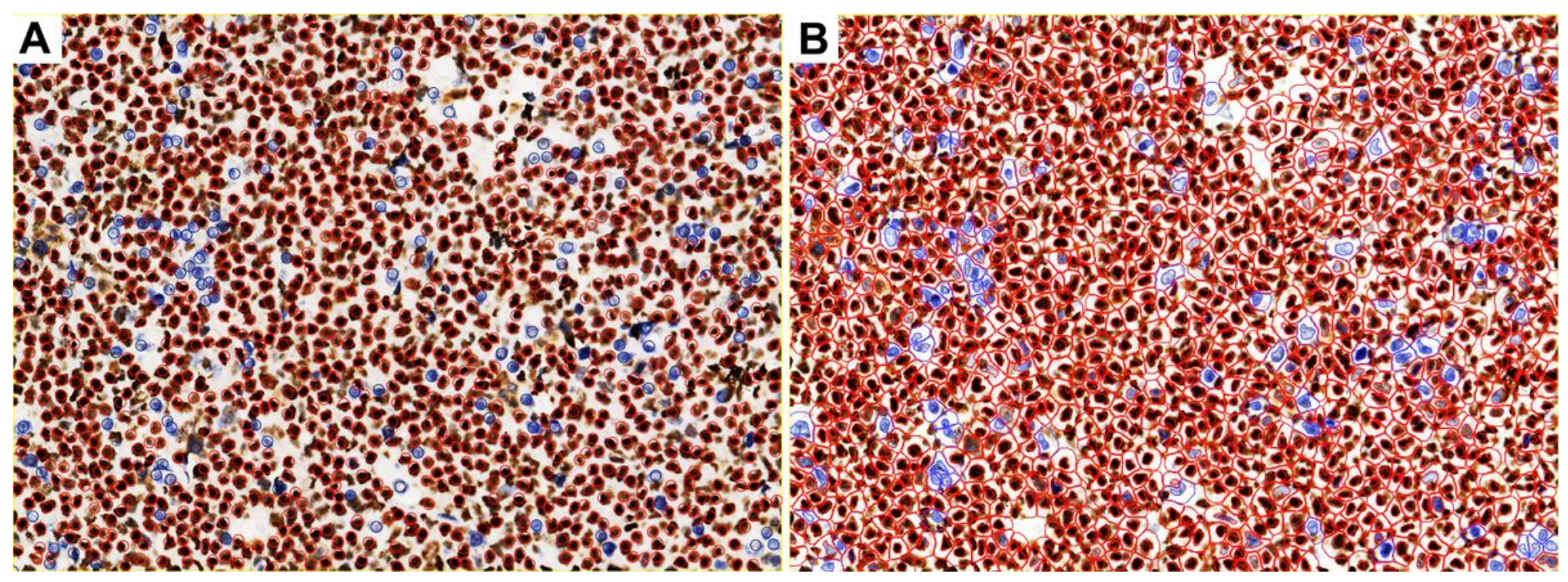

Figure 1

Image analysis of p53-positive tumor cells in identical areas of a randomly chosen specific region in one case. (A) Image-based manual counting. Positively stained (brown) and negative nuclei (blue) are marked with red and blue circles. (B) Image-based computer image analysis. Positively stained (brown) and negative nuclei (blue) are marked with red and blue irregular circles. 


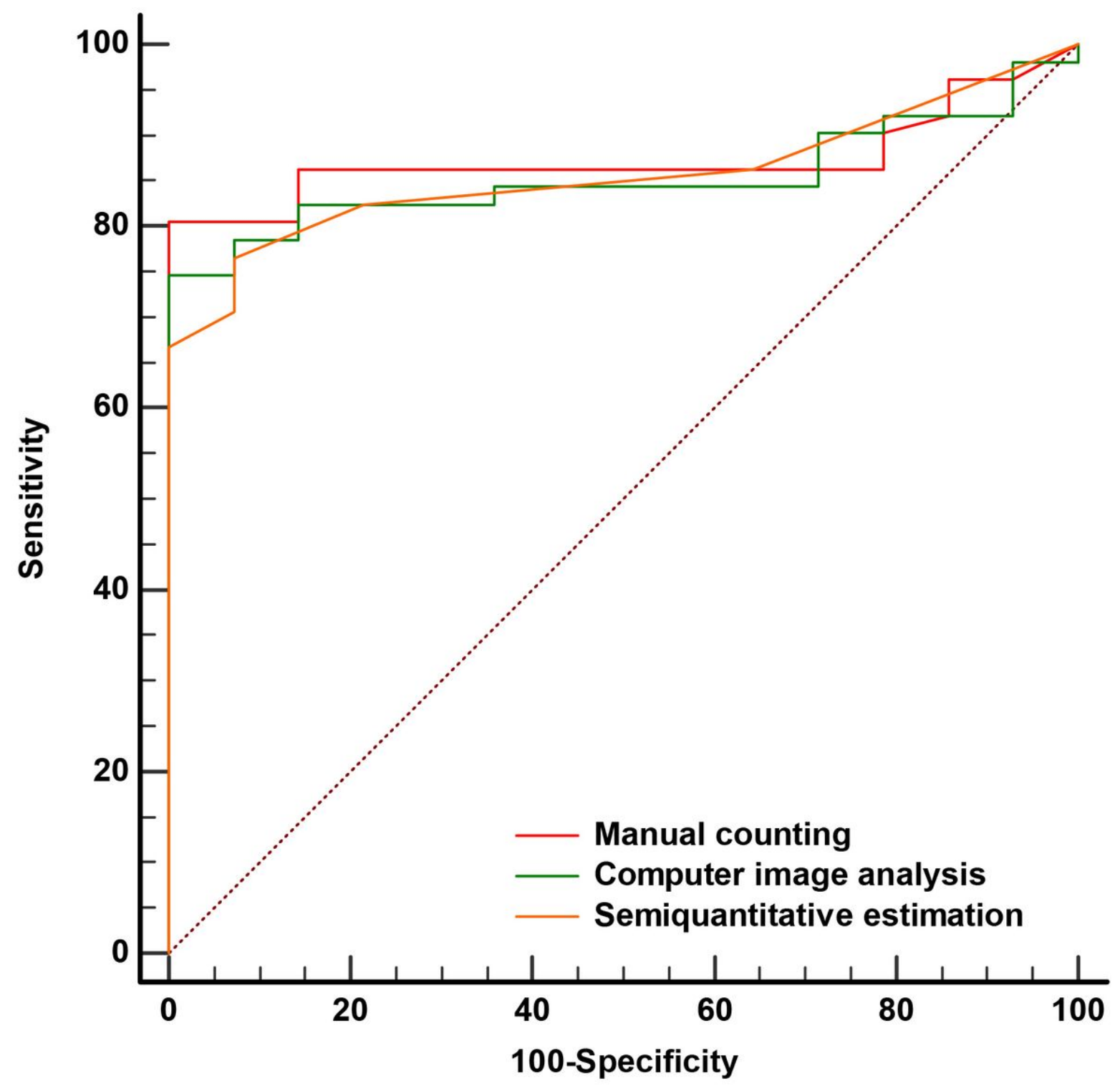

Figure 2

Discriminatory power of p53 for predicting overall survival (OS). 

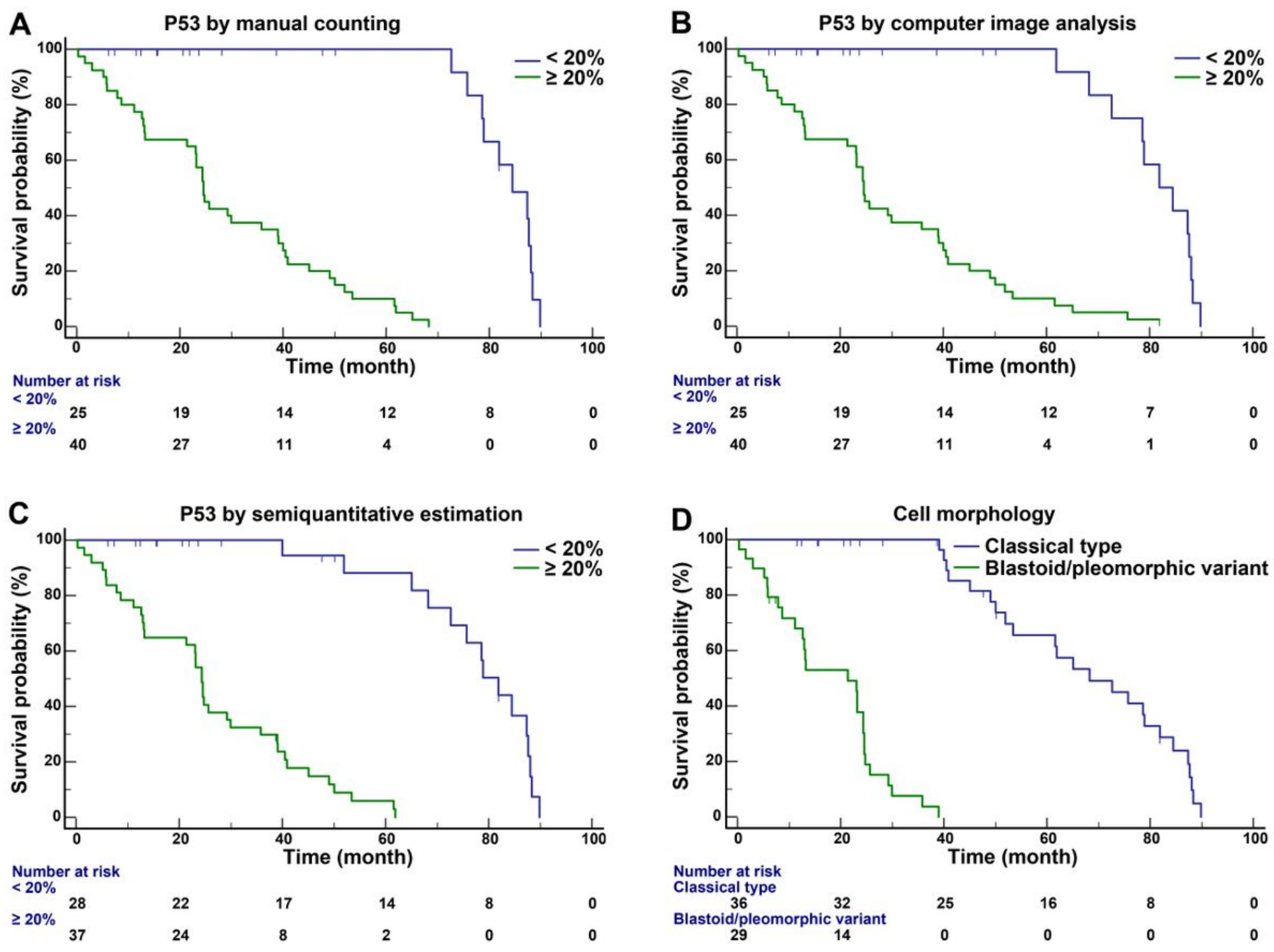

Figure 3

Overall survival (OS) according to (A) p53 by manual counting, (B) p53 by computer image analysis, (C) p53 by semiquantitative estimation, and (D) classical type versus blastoid/pleomorphic variant cell morphology. 

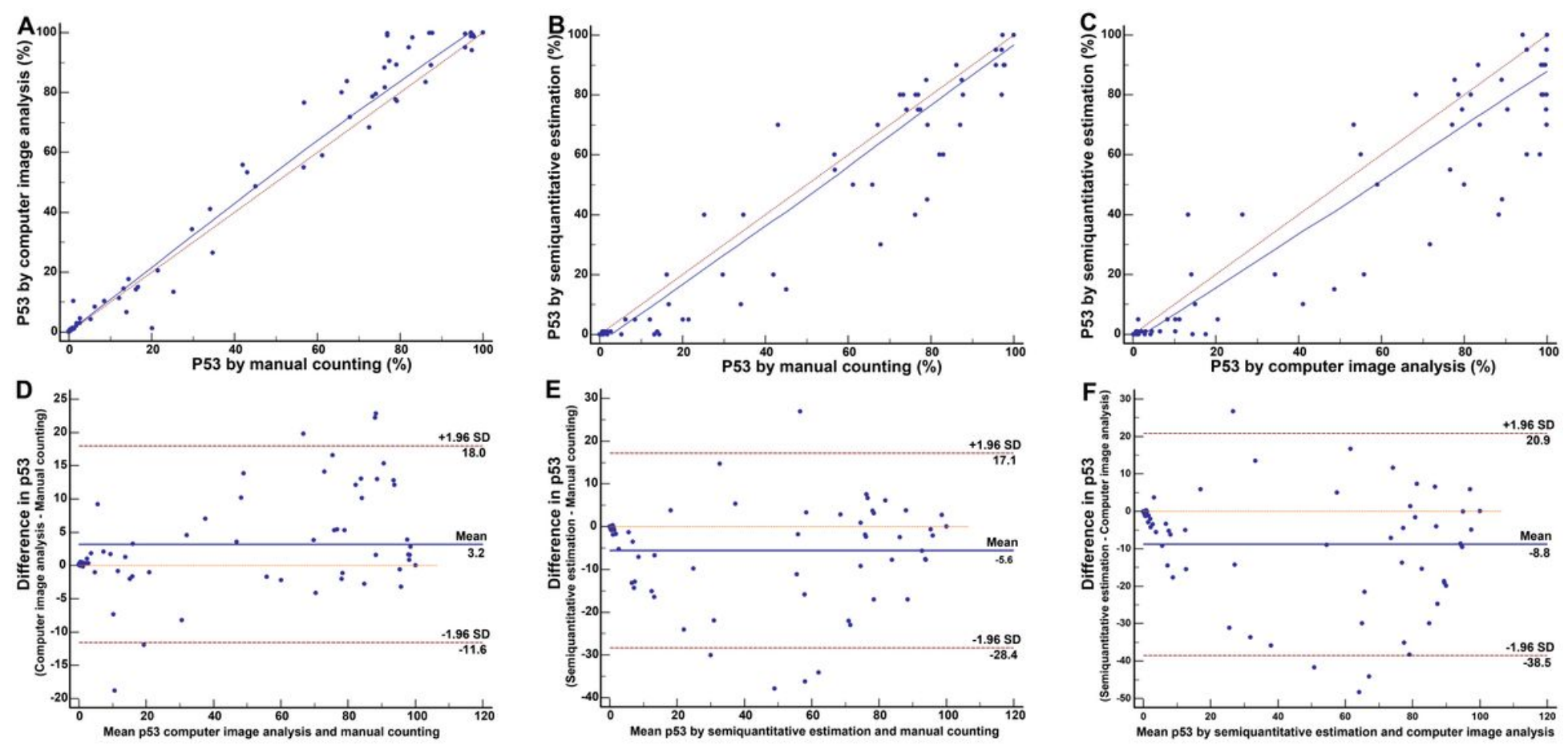

Figure 4

Correlation between (A) computer image analysis and manual counting of p53, (B) semiquantitative estimation and manual counting of p53, and (C) semiquantitative estimation and computer image analysis of p53 in identical areas. Bland-Altman plots comparing p53 by (D) computer image analysis with manual counting, (E) semiquantitative estimation with manual counting, and (F) semiquantitative estimation with computer image analysis of identical areas.

\section{Supplementary Files}

This is a list of supplementary files associated with this preprint. Click to download.

- Graphicalabstract.jpg 